\title{
Evolution of plant resistance at the molecular level: ecological context of species interactions
}

\author{
J de Meaux and T Mitchell-Olds \\ Department of Genetics and Evolution, Max Planck Institute for Chemical Ecology, Winzerlaer Strasse 10, 07745 Jena, Germany
}

\begin{abstract}
Molecular data regarding the diversity of plant loci involved in resistance to herbivores or pathogens are becoming increasingly available. These genes demonstrate variable patterns of diversity, suggesting that they differ in their evolutionary history. In parallel, the study of natural variation for resistance, generally conducted at the phenotypic level, has shown that resistance does not evolve solely under selection pressures exerted by enemies. Metapopulation dynamics and other ecological characteristics of interacting
\end{abstract}

species also appear to have a large impact on resistance evolution. Until now, studies of resistance at the molecular level have been conducted separately from ecological studies in extant populations. Future progress requires an evolutionary approach integrating both molecular and ecological aspects of resistance evolution. Such an approach will contribute greatly to our understanding of the evolution of molecular diversity at loci involved in biotic stress. Heredity (2003) 91, 345-352. doi:10.1038/sj.hdy.6800342

Keywords: resistance; evolution; molecular diversity; metapopulation; ecology; coevolution

\section{Introduction}

Genetic variation for resistance to herbivores and microbial pathogens is widespread in plant populations, yet the ecological and evolutionary forces influencing this variation remain unclear. Genetic determination of resistance may be polygenic (eg, Wilson et al, 2001; Kliebenstein et al, 2002b) or may be influenced by single genes with major effects (Flor, 1956; Rossi et al, 1998). Functional genomics analyses using induced mutations and transgenics provide a greater understanding of resistance mechanisms (Dodds and Schwechheimer, 2002). In addition, molecular population genetic analysis of patterns of nucleotide polymorphism within and between populations at known resistance loci can detect the signature of natural selection (Fay and $\mathrm{Wu}, 2001$; Nordborg and Innan, 2002).

A variety of molecular diversity patterns are observed at the plant resistance loci examined to date, suggesting that selection varies among loci. Most molecular studies of resistance loci provide little information on ecological or geographic patterns of functional variation. The ecological and historical context can, nonetheless, markedly impact patterns of nucleotide diversity. Recent theoretical work incorporating the metapopulation structure into the coalescent process has shown that almost any pattern of polymorphism frequency distribution can be generated at a neutral locus (Wakeley and Aliacar, 2001). Whether current or past ecological factors may explain the different evolutionary trajectories observed for defense-related genes remains to be

Correspondence: T Mitchell-Olds, Department of Genetics and Evolution, Max Planck Institute for Chemical Ecology, Winzerlaer Strasse 10, 07745 Jena, Germany. E-mail: tmo@ice.mpg.de

Received: 10 June 2003 examined. Analyses of natural variation for resistance in extant populations, although generally conducted at the whole-plant level rather than at the molecular level, have begun to elucidate how the ecological configuration of species interactions can influence evolutionary outcomes. The results of these studies can help bring a broader context to the assessment and interpretation of molecular diversity at resistance loci.

\section{Resistance to pathogens and herbivores}

Plant defense against insects and microbial pathogens can be divided into three conceptual phases: attack recognition, signal transduction, and defense deployment. Many recognition genes controlling resistance to specific pathogen strains (R-genes) have been cloned. Generally, these R-genes share homologous functional domains, and can occur either as isolated genes, or more commonly as tandem clusters (reviewed in Michelmore and Meyers, 1998; Dixon et al, 2000; Richly et al, 2002; Meyers et al, 2003). Analyses of diversity at different Rgenes have identified several molecular mechanisms responsible for the generation of diversity at these loci. Adaptive evolution resulting from mutations on the solvent-exposed residues of leucine-rich repeats (LRR) has been shown, presumably enabling detection of variable pathogen-related ligands (Parniske et al, 1997; Meyers et al, 1998; Noel et al, 1999; Dixon et al, 2000; Sun et al, 2001). In addition, recombination plays an important role in generating new LRR configurations (McDowell et al, 1998; Luck et al, 2000) and new paralogues at complex loci (Parniske et al, 1997; Meyers et al, 1998; Sun et al, 2001). However, mutation and recombination seem to differentially affect R-gene families, which vary in their density and positioning along the chromosome (Parniske et al, 1997; Meyers et al, 
1998), in their copy numbers (Meyers et al, 1998; Noel et al, 1999), in the proportion of nonfunctional genes (Parniske et al, 1997; Noel et al, 1999; Sun et al, 2001), in divergence levels among paralogues (Wei et al, 1999; Sun et al, 2001), and in relative rates of recombination (Wei et al, 1999; Sun et al, 2001). The cause of these differences among loci is not yet understood.

In plant-insect interactions, the molecular mechanisms underlying the recognition of herbivore attack are not well known. However, some features are shared with plant-pathogen interactions. Although most genetic variation governing plant-insect interactions is probably polygenic (eg, Kliebenstein et al, 2002b), single genes responsible for plant resistance have been documented in several instances. For example, in the interaction between wheat and the hessian fly, Mayetiola destructor, resistance is governed by single genes, and a variety of resistance polymorphisms are found in cultivars and wild relatives of wheat (Zaharieva et al, 2001). Likewise, resistance to Asian rice gall midge is controlled by a single dominant locus (Katiyar et al, 2001). Recent data also indicate that resistance to herbivores and pathogens can involve similar signaling pathways. For example, an LRR gene was shown to be responsible for both aphid and nematode resistance in tomato (Rossi et al, 1998). This LRR gene is very similar to the tomato Prf gene, which is required for resistance to the bacterial pathogen Pseudomonas syringae (Rossi et al, 1998).

Signal transduction pathways influencing plant defense responses are discussed extensively in the literature (reviewed in Glazebrook, 2001; Kessler and Baldwin, 2002). Cross talk among responses to insects and pathogens may be mediated by common signaling pathways (Cui et al, 2002). For example, ethylene influences resistance to bacterial and fungal pathogens, lepidopteran herbivores, and nematodes (Wang et al, 2002). So far, little information is available on genetic variation in these regulatory pathways, although quantitative trait loci (QTLs) influencing induction of defensive metabolites have recently been mapped (Kliebenstein et al, 2002a).

\section{Patterns of genetic variation at resistance loci}

Intraspecific genetic variation for resistance has been shown for a number of plant-pathogen and plant-insect interactions in the wild (Fritz and Simms, 1992; Burdon et al, 1996). Experimental analyses are especially straightforward when major gene polymorphisms control host resistance, even if the responsible locus has not been cloned. Polymorphisms for resistance are generally detected even when hosts and pathogens originate sympatrically. For example, Clarke et al (1987) studied the interaction between the plant Senecio vulgaris and its rust Erysiphe fischeri, using 10 pathogen strains and 150 plants from a $6-\mathrm{km}^{2}$ area. As many as 24 major resistance phenotypes were detectable in this host population. High amounts of molecular diversity both within and among natural populations have also been detected at complex R-loci in Lactuca spp., Lycopersicon pimpinellifolium and Phaseolus vulgaris (Sicard et al, 1999; Neema et al, 2001; Van der Hoorn et al, 2001), and for concentrations of furanocoumarins, which deter herbivores attacking Pastinaca sativa (Berenbaum and Zangerl, 1998). Although genetic variation is common, some host populations appear to lack detectable variation for resistance to insects or pathogens (Nakamura et al, 1995; Burdon and Thrall, 1999).

Genes experiencing natural selection can be identified by levels of polymorphism that are either increased or decreased relative to neutral molecular variation (reviewed in Ford, 2002). Reduced levels of nucleotide polymorphism may result from a selective sweep, where an advantageous genetic variant has recently risen to high frequency, causing older genetic variants to be eliminated from the population. Such examples of positive Darwinian selection may reflect an 'evolutionary arms race' between host and enemy species (Bergelson et al, 2001b; Holub, 2001). Alternatively, elevated levels of nucleotide polymorphism may indicate ancient genetic variation maintained by balancing selection. This mode of host-enemy interaction has been termed 'trench warfare' (Stahl et al, 1999) or 'recycling polymorphism' (Holub, 2001).

Analyses of nucleotide diversity indicate that balancing selection may maintain polymorphism at some R-genes for long periods of time, perhaps reflecting longterm trench warfare between host and pathogen genotypes (Bergelson et al, 2001b; Holub, 2001). In Arabidopsis thaliana, very high levels of nucleotide variation surround resistance polymorphisms at Rpm1, and similar observation were made on other LRR-class R-genes (Stahl et al, 1999; Bergelson et al, 2001b; Tian et al, 2002; Mauricio et al, 2003). In contrast, variation at the Rps4 LRR resistance locus suggests a recent selective sweep that is typical of an 'evolutionary arms race', since resistant and susceptible alleles are almost identical at the nucleotide level (Bergelson et al, 2001b).

Natural genetic variation also occurs in the deployment of metabolites and proteins that provide direct defense against herbivores and microbial pathogens. Glucosinolates and their breakdown products are genetically variable in Arabidopsis and Brassica, and experience natural selection due to their biological effects on generalist and specialist herbivores (Mauricio and Rausher, 1997; Raybould and Moyes, 2001; Kliebenstein et al, 2002b). High levels of nucleotide polymorphism are maintained by balancing selection at the Arabidopsis GSelong locus (Kroymann and Mitchell-Olds, unpublished), which encodes a glucosinolate biosynthetic enzyme (Kroymann et al, 2001). Evolutionary forces influencing families of metabolites have also been investigated. In Datura stramonium, insect herbivory imposes selection on the synthesis of two major alkaloids present in leaf tissue (Shonle and Bergelson, 2000). In the plant Pastinaca sativa, the production of sphondin, a defense metabolite, seems to have been selected during the last 100 years, as indicated by increased sphondin production levels (Berenbaum and Zangerl, 1998).

Two loci in maize, $h m 1$ and $h m 2$, encode enzymes that degrade a toxin produced by the fungal pathogen Cochliobolus carbonum (see Zhang et al, 2002). Segregating $h \mathrm{~m} 1$ alleles have large functional effects on disease resistance, whereas segregating $h \mathrm{~m} 2$ alleles have moderate effects causing partial resistance to Cochliobolus. Nucleotide polymorphism at the hml locus showed high levels of neutral variation, whereas the $h m 2$ locus had low levels of segregating polymorphism (Zhang et al, 2002). Despite the greater functional variation at $h m 1$, 
only $h m 2$ shows significant deviation from an equilibrium neutral model, apparently due to a selective sweep for detoxification ability. Another defensive enzyme, myrosinase, also shows evidence for a recent selective sweep in A. thaliana (Stranger, 2002). Following tissue damage, myrosinase catalyzes breakdown of glucosinolates into defensive metabolites that are toxic to many insects and pathogens. Ancestral alleles at the tgg1 myrosinase-encoding locus have low levels of enzyme activity, whereas recent (derived) mutations show high levels of myrosinase activity. Derived tgg1 alleles constitute the predominant alleles in a worldwide sample of $A$. thaliana genotypes, as expected for a recent selective sweep favoring increased myrosinase activity.

Long-term evolutionary dynamics occurring between enzymes and inhibitors in plant-pest interactions have also been examined. In plant class I chitinase, nonsynonymous substitution rates exceed synonymous rates in Arabis and other dicots (Bishop et al, 2000). Individual residues experiencing positive selection were identified relative to the three-dimensional structural model of chitinase. Adaptive replacements occur disproportionately in the active site cleft of the enzyme, suggesting that chitinolytic activity in plants responds to inhibitor evolution in fungal pathogens. Likewise, adaptive molecular evolution occurs in plant polygalacturonase inhibitor proteins (Stotz et al, 2000), which bind fungal polygalacturonases. Finally, nucleotide polymorphism at the wip1 wound-inducible serine protease inhibitor locus in the Zea genus was shown not to differ from neutral expectations (Tiffin and Gaut, 2001). Relative rate tests indicated, however, an accelerated rate of evolution in this genus, suggesting that natural selection at the wip 1 locus may either occur episodically or favor novel alleles.

Current data reveal no tendency for the recognition or deployment phases of plant defense to evolve preferentially via trench warfare versus an evolutionary arms race (Stahl et al, 1999; Bergelson et al, 2001b; Kroymann et al, 2001; Stranger 2002; Zhang et al, 2002). Rather, balancing selection maintains ancient nucleotide polymorphisms at resistance loci encoding LRR recognition proteins and secondary metabolic enzymes (eg, Rpm1, Rps5, Rps2, GSelong). Likewise, selective sweeps may escalate evolutionary arms races at LRR genes or plant enzymes active in secondary metabolism or degradation of microbial compounds (eg, Rps4, hm2, and tgg1). Furthermore, currently available tests of neutrality have little power for the detection of selection regimes that do not belong to either of these two evolutionary extremes (eg, hm2, wip1).

\section{Genetic models for the maintenance of polymorphism}

Maintenance of genetic variation for resistance cannot be readily explained by simple population genetic models because resistance genes are predicted to become fixed within populations due to the fitness advantage they provide to the host (Bergelson et al, 2001a). Numerous theoretical studies have sought ecological or evolutionary explanations for the frequent observation of resistance polymorphism. Based on the simple genetic determinism emerging from Flor's work (1956), models of resistance evolution have led to the idea that negative frequency-dependent selection might maintain resistance polymorphisms in host plants (reviewed in Leonard, 1997; Bergelson et al, 2001a). Thus, frequency-dependent selection has been invoked to explain maintenance of polymorphisms in $A$. thaliana and $L$. pimpinellifolium (Stahl et al, 1999; Bergelson et al, 2001b; Van der Hoorn et al, 2001).

Simple gene-for-gene models predict stable polymorphisms through frequency-dependent selection provided there are costs associated with resistance and virulence (Leonard, 1997). Recent progress towards understanding resistance and virulence mechanisms at the protein level may improve evolutionary interpretation of host-enemy polymorphisms. Mackey et al (2002) have shown that the AvrRpm1 avirulence protein of Pseudomonas syringae interacts directly with RIN4, a hostencoded negative-regulator of plant defense processes. The Arabidopsis Rpm1 protein is a 'molecular guard' that prevents AvrRpm1 from downregulating host defenses. Preliminary data indicate that this guarding mechanism may be broadly applicable (De Wit, 2002; Van der Hoorn et al, 2002). This finding not only elucidates the function of avirulence genes but also explains how the loss of an avirulence allele can affect pathogen fitness. It consequently offers one mechanism by which R-genes may detect indispensable virulence factors and thus provide durable defense (Van der Hoorn et al, 2002). Balancing selection is therefore hypothesized to act primarily on Rgenes that aim at such avirulence genes (Van der Hoorn et al, 2002).

This molecular guard hypothesis requires a fitness cost associated with resistant alleles (Leonard, 1997; Van der Hoorn et al, 2002). Indeed, in a landmark study controlling efficiently for background effects, the presence of the resistant RPM1 allele was shown to cause a $9 \%$ decrease in fitness when the pathogen was absent (Tian et al, 2003). Recent reviews have concluded that costs of resistance are common in many plant-enemy interactions (Strauss et al, 2002). However, in natural populations, 'unnecessary' R-genes seem to be widespread. For example, in wild bean, plants from the Central American gene pool display more resistance to pathogen strains from the South Andean gene pool than to pathogens found locally (Geffroy et al, 1999). This suggests that costs to resistance are generally lower than what was observed at the RPM1 locus (Bergelson and Purrington, 1996; Tian et al, 2003), and may not be sufficient for maintenance of genetic polymorphism. Alternatively, 'unnecessary' R-genes could be maintained despite their costs due to residual effects on defense. Recently, residual functions of 'defeated' resistance alleles have been shown to depend on the genetic background of both hosts and pathogens, as well as on the resistance gene considered ( $\mathrm{Li}$ et al, 2001). However, the existence of costs is crucial only in the context of purely genetic models, in which evolution of resistance and virulence are solely determined by the interaction between gene products in the host and the enemy. Models incorporating other factors such as population dynamics and geographical structure indicate that the maintenance of polymorphisms does not necessarily require costs (Thrall and Burdon, 2002) (see below). 
Frequency-dependent selection alone does not explain plant-enemy coevolution

Studies of resistance variation in wild populations suggest that negative frequency-dependent selection alone is not sufficient to explain the complex evolutionary trajectories observed in actual populations. Firstly, negative frequency-dependent selection has been difficult to document in field experiments or natural populations. For example, Brunet and Mundt (2000) found evidence for frequency-dependent selection only in a sub-sample of field populations, where it did not maintain genetic polymorphisms. Support for frequencydependent selection is also inconsistent in natural populations. In the interaction between the plant Chondrilla juncea and its rust Puccinia chondrillina, disease primarily occurs in the most common genotypes, as expected under frequency-dependent selection (Chaboudez and Burdon, 1995). However, this pattern was not found in the interaction between Boechera holboellii and Puccinia rusts (Roy, 1993). Finally, several studies have also shown maladaptive changes where susceptible host genotypes increase in frequency (Parker, 1991; Burdon and Thrall, 1999).

Several factors may counteract theoretical predictions of simple frequency-dependent models. First, models incorporating finite size populations show that conditions for maintenance of polymorphism may be more restrictive (Kirby and Burdon, 1997). Second, particularly in the case of inbreeding species, linkage disequilibrium with nonresistance traits can affect the response to selection (Parker, 1991). For frequency-dependent selection to be efficient, sex and recombination may be required, allowing a rapid response to changing pathogen populations (Clay and Kover, 1996). For example, Burdon and Marshall (1981) found that biological control programs have been more successful against inbred weeds than against outbred plant species. Nevertheless, many asexual or inbred plant species (eg, B. holboellii, A. thaliana, A. bracteata, $P$. vulgaris) prosper despite attacks by herbivore and pathogen species. Third, parasite selection pressure must be sufficiently strong to cause changes in host resistance frequencies (Clay and Kover, 1996). However, in the wild, many pathogens as well as herbivores do not necessarily cause death of the host, and the selection pressure they exert can be minor in comparison with other stresses (Raybould and Moyes, 2001).

Demographic factors may also have important effects on the evolution of resistance in host populations, because epidemics generally lead to population reductions, causing bottlenecks and/or genetic drift. Frank (1992) proposed a model incorporating demographic variation, and showed that the maintenance of resistance genes in a host population depends primarily on the growth rate of the pathogen, which influences the probability of massive epidemics. As a consequence, epidemiological characteristics of a pathogen may have a major impact upon resistance evolution, whereas frequency-dependent selection may play a secondary role.

\section{Geographic landscape of interactions}

Geographic variation for resistance and virulence is common in many host-enemy interactions. Most host populations are genetically differentiated for resistance and pathogen populations are often differentiated for virulence (eg, Sicard et al, 1997; Cattan-Toupance et al, 1998; Althoff and Thompson, 1999; Burdon and Thrall, 1999). This geographic heterogeneity may cause unique ecological and evolutionary dynamics at different locations (Thompson, 1999). Geographic heterogeneity is influenced by abiotic factors such as climate (see Burdon and Thrall, 1999), but also by biotic factors such as the presence of additional species, and metapopulation characteristics like migration and spatial scale (below).

Competitors can affect the pattern of selection exerted on the host. For example, a quantitative genetics field experiment of Ipomoea hederacea resistance to deer and insect herbivory indicates that resistance to these two natural enemies is not genetically independent, and that the presence or absence of insects affects selection on deer resistance (Stinchcombe and Rausher, 2001). Thus, the spatial distribution of competitors can result in geographic patterns in interacting species. For instance, in natural populations of lodgepole pine and crossbills (Benkman et al, 2001), coevolution in adaptive traits of both host and predator was shown in populations where a competitor, the squirrel Tamiasciurus hudsonicus, is absent, but not in populations where its presence makes crossbills a minor seed predator.

Species generally consist of numerous populations that are genetically heterogeneous (Hughes et al, 1997), hence levels of gene flow in host and enemy metapopulations can substantially affect the evolutionary dynamics of an interaction. Patterns of local adaptation of a parasite to its sympatric hosts provide an interesting illustration of the impact that dispersal across heterogeneous populations has upon evolutionary interactions. In a model explicitly incorporating the spatial structure of host and parasite populations, Gandon et al (1996) showed that local adaptation of the pathogen is favored when the pathogen migrates more than its host or when both migrate very little. These results correspond well to several empirical studies where interacting species vary over both space and time (Gandon et al, 1996; Kaltz and Shykoff, 1998; Mopper et al, 2000).

Geographic distance, reflecting variation in gene flow, also affects patterns of resistance diversity and their spatial and temporal evolution. For example, Burdon and Thrall (2000) reported a spatially structured analysis of the flax-rust interaction. The influence of the antagonistic interaction between flax and its rust upon the evolution of host resistance was detected only at a broad spatial scale, whereas stochasticity appeared to dominate resistance evolution at local scales. Similar features emerge from the interaction between $P$. vulgaris and Colletotrichum lindemuthianum, although the dispersal characteristics of this species-pair differs from the flax-rust interaction. (Sicard et al, 1997; Cattan-Toupance et al, 1998; Neema et al, 2001; de Meaux et al, 2003)

In an attempt to clarify the complex patchwork of evolutionary forces emerging from the study of diversity across multiple populations, Thompson (1999) proposed the geographic mosaic hypothesis to model coevolutionary interactions in natural populations. This theory identifies three elements influencing the coevolutionary process among interacting species. Firstly, variability in reciprocal selection pressure creates a geographic mosaic in which coevolution proceeds. Secondly, pairwise coevolutionary changes occur in a subset of populations 
where reciprocal selection pressures are strongest ('hot spots'). Finally, gene flow among populations causes continual geographic mixing of coevolving traits. Thus, the geographic mosaic hypothesis seeks to understand global evolutionary changes on the basis of spatial variation of local species interactions. If the outcomes of interactions are affected by geographical structure, then local coevolution is predicted to occur. However, direct evidence for reciprocal coevolutionary changes remains scarce, although rapid evolutionary changes following alterations of selection configurations are commonly observed (Thompson, 1998).

Recently, Thompson and Cunningham (2002) showed that fitness consequences of interspecific interactions can be highly divergent among local populations. They quantified geographic heterogeneity of selective forces exerted by an insect parasite on its host plant, Lithophragma parviflorum, over a number of populations. The direction of selection varied from antagonistic to mutualistic among populations, presumably due to variation in co-occurring pollinator assemblages. This heterogeneous species interaction provides the ecological context for a geographic evolutionary mosaic. Further work will be necessary to show reciprocal coevolutionary changes within 'hot spots', as well as gene flow with surrounding 'cold spots'. The potential for such exchanges has already been shown by studies of molecular diversity in the host and parasite species (Thompson, 1997).

Theoretical models have begun to explore the impact of geographic structure upon dynamics of interactions, yielding predictions very different from large, homogeneous populations. For instance, Gomulkiewicz et al (2000) show that the spatial distribution of 'hot' and 'cold' spots can influence strongly the coevolutionary dynamics. Gene flow, natural selection and habitat size were also shown to influence evolution of interactionrelated characters, and to be crucial determinants of an appropriate geographical scale for examining coevolutionary changes (Nuismer et al, 1999). More importantly, extinction and recolonization dynamics were shown to have a major impact on the evolutionary outcome of interactions, both with regard to how the epidemic develops and to how the genetic composition of interacting species changes over generations (Thrall and Burdon, 2002). Such dynamics allow maintenance of resistance and virulence polymorphisms without the existence of costs. Consequently, the debate about costs of resistance and virulence may not be fundamental to the maintenance of genetic variation.

\section{Guidelines for analysis of molecular diversity at interaction loci}

To study the genes that matter in ecology, we must examine individual loci with known functional effects. Several excellent molecular studies (above) have examined allelic polymorphisms for resistance traits in plant populations. The future challenge is to combine these approaches with greater ecological realism and relevance. Prior to any ecological and population-wide study, natural polymorphisms among alleles that differ in function must be identified. Genetically tractable species that are closely related to well-studied model organisms will be particularly useful for this endeavor (Mitchell-Olds, 2001).

As we have seen, realistic models and data from natural populations are far more complex than portrayed by frequency dependent selection in a single infinite population. Other factors such as metapopulation structures of interacting species, life history traits, breeding system, and competitors can affect the observed patterns of resistance diversity. These factors need to be integrated in the study of molecular diversity at resistance loci and should help to determine ecologically relevant sampling of diversity.

To understand the processes of host-enemy interactions at the molecular level, diversity should be sampled in metapopulations that are relatively undisturbed. Studies of introduced species may yield incongruent evolutionary and ecological inferences. This can occur because molecular population genetics identifies historical patterns which accumulated over thousands of generations in ancestral environments, whereas ecological analyses of introduced plants may exclude the enemy species which were responsible for the evolutionary forces revealed by nucleotide polymorphism. Thus, wild relatives of genetically tractable organisms, such as Arabidopsis lyrata, Oryza rufipogon, Lotus corniculatus, Medicago truncatula, as well as wild species with well known histories such as Linum marginale, Phaseolus vulgaris or Lycopersicon pimpinellifolium, may be useful for such studies.

Phenotypic studies of resistance evolution have shown that host population dynamics can have a large impact on the evolution of resistance and can be a major evolutionary force. Studying resistance alone does not allow discrimination between stochastic and interactionspecific evolutionary forces. As evolutionary forces related to population structure and dynamics affect the whole genome, diversity at neutral loci can be contrasted to ecologically important genes (Wakeley and Aliacar, 2001). Stochastic and coevolutionary forces are unlikely to act in a simple additive manner, and the mode in which they interact is one of the keys to understanding these systems. Simultaneous analysis of neutral and ecologically important variability at multiple spatial scales offers one way to characterize the relative importance of genetic isolation versus selection by antagonistic species (Burdon and Thrall, 2000; de Meaux et al, 2003). Eventually, elucidation of selective forces shaping resistance evolution requires joint analysis of the geographic distribution and dynamics of host and enemy populations. The characterisation of the geographic mosaics of selection is likely to play a crucial role in the interpretation of molecular diversity at resistance genes (Gomulkiewicz et al, 2000; Thompson and Cunningham, 2002).

\section{Conclusion}

Ancient allelic polymorphisms as well as recent selective sweeps are found at the few resistance loci that have been studied to date (Bergelson et al, 2001b). However, when the evolutionary history of genes does not correspond to these extremes, evolutionary interpretation can be difficult (Tiffin and Gaut, 2001; Zhang et al, 2002). On the other hand, ecological analyses of resistance diversity in natural populations indicate that 
evolutionary dynamics are influenced not only by selection but also by host population dynamics and the geographical distribution of species. An ecologically relevant sampling of molecular variation at both neutral and defense-related loci should help elucidate the causes of selection and the resultant patterns of diversity. In the future, understanding the causes of allele maintenance in nature will be crucial for identifying the conditions in which resistance can be sustainable in agriculture (Stuthman, 2002).

\section{Acknowledgements}

We thank M Clauss, B Gaut, C Knight, J Kroymann, S Ramos-Onsins, C Wheat and A Windsor for helpful discussion and comments on the manuscript. TMO was supported by the European Union (Contract number QLRT-2000-01097), the Bundesminesterium für Bildung und Forschung, the US National Science Foundation (Grant DEB-9527725), and the Max Planck Gesellschaft.

\section{References}

Althoff DM, Thompson JN (1999). Comparative geographic structures of two parasitoid-host interactions. Evolution 53: 818-825.

Benkman CW, Holimon CW, Smith JW (2001). The influence of a competitor on the geographic mosaic of coevolution between crossbills and lodgepole pine. Evolution 55: 282-294.

Berenbaum MR, Zangerl AR (1998). Chemical phenotype matching between a plant and its insect herbivore. Proc Natl Acad Sci USA 95: 13743-13748.

Bergelson J, Purrington CB (1996). Surveying patterns in the cost of resistance in plants. Am Nat 148: 536-558.

Bergelson J, Dwyer G, Emerson JJ (2001a). Models and data on plant-enemy coevolution. Annu Rev Genet 35: 469-499.

Bergelson J, Kreitman M, Stahl EA, Tian DC (2001b). Evolutionary dynamics of plant R-genes. Science 292: 2281-2285.

Bishop JG, Dean AM, Mitchell-Olds T (2000). Rapid evolution in plant chitinases: molecular targets of selection in plantpathogen coevolution. Proc Natl Acad Sci USA 97: 5322-5327.

Brunet J, Mundt CC (2000). Disease, frequency-dependent selection, and genetic polymorphisms: experiments with stripe rust and wheat. Evolution 54: 406-415.

Burdon JJ, Marshall DR (1981). Biological control and the reproductive mode of weeds. J Appl Ecol 18: 649-658.

Burdon JJ, Wennström A, Elmqvist T, Kirby GC (1996). The role of race specific resistance in natural plant populations. Oikos 76: 411-416.

Burdon JJ, Thrall PH (1999). Spatial and temporal patterns in coevolving plant and pathogen associations. Am Nat 153: S15-S33.

Burdon JJ, Thrall PH (2000). Coevolution at multiple spatial scales: Linum marginale - Melampsora lini - from the individual to the species. Evol Ecol 14: 261-281.

Cattan-Toupance I, Michalakis Y, Neema C (1998). Genetic structure of wild bean populations in their South-Andean centre of origin. Theor Appl Genet 96: 844-851.

Chaboudez P, Burdon JJ (1995). Frequency-dependent selection in a wild plant-pathogen system. Oecologia 102: 490-493.

Clarke DD, Bevan JR, Crute IR (1987). Genetic interactions between wild plants and their parasites. In: Day PR, Jellis GJ (eds) Genetic and Plant Pathogenesis. Blackwell Scientific Publications: Oxford. pp. 195-206.

Clay K, Kover PX (1996). The red queen hypothesis and plant/ pathogen interactions. Annu Rev Phytopathol 34: 29-50.

Cui J, Jander G, Racki LR, Kim PD, Pierce NE, Ausubel FM (2002). Signals involved in arabidopsis resistance to Trichoplusia in caterpillars induced by virulent and avirulent strains of the phytopathogen Pseudomonas syringae. Plant Physiol 129: 551-564.

De Meaux J, Cattan-Toupance I, Lavigne C, Langin T, Neema C (2003). Polymorphism of a complex resistance gene candidate family in wild populations of common bean (Phaseolus vulgaris) in Argentina: comparison with phenotypic resistance polymorphism. Mol Ecol 12: 263-273.

De Wit PJGM (2002). On guard. Nature 416: 801-803.

Dixon MS, Golstein C, Thomas CM, van der Biezen EA, Jones JDG (2000). Genetic complexity of pathogen perception by plants: the examples of Rcr3, a tomato gene required specifically by Cf2. Proc Natl Acad Sci USA 97: 8807-8814.

Dodds PN, Schwechheimer C (2002). A breakdown in defense signaling. Plant Cell 14: S5-S8.

Fay JC, Wu CI (2001). The neutral theory in the genomic era. Curr Opin Gen Dev 11: 642-646.

Flor H (1956). The complementary genic systems in flax and flax rust. Adv Genet 8: 29-54.

Ford MJ (2002). Application of selective neutrality tests to molecular ecology. Mol Ecol 11: 1245-1262.

Frank SA (1992). Models of plant-pathogen coevolution. Trends Genet 8L: 213-219.

Fritz RS, Simms EL (1992). Plant Resistance to Herbivores and Pathogens: Ecology, Evolution, and Genetics. University of Chicago Press: Chicago.

Gandon S, Capowiez Y, Dubois Y, Michalakis Y, Olivieri I (1996). Local adaptation and gene-for-gene coevolution in a metapopulation model. Proc Natl Acad Sci USA 263: 1003-1009.

Geffroy V, Sicard D, de Oliveira JCF, Sévignac M, Cohen S, Gepts $P$ et al (1999). Identification of an ancestral resistance gene cluster involved in the coevolution process between Phaseolus vulgaris and its fungal pathogen Colletotrichum lindemuthianum. Mol Plant-Microbe Interact 12: 774-784.

Glazebrook J (2001). Genes controlling expression of defense responses in Arabidopsis - 2001 status. Curr Opin Plant Biol 4: 301-308.

Gomulkiewicz R, Thompson JN, Holt RD, Nuismer SL, Hochberg ME (2000). Hot spots, cold spots, and the geographic mosaic theory of coevolution. Am Nat 156: 156-174.

Holub EB (2001). The arms race is ancient history in Arabidopsis, the wildflower. Nat Rev Genet 2: 516-527.

Hughes JB, Daily GC, Ehrlich PR (1997). Population diversity: its extent and extinction. Science 278: 689-692.

Kaltz O, Shykoff JA (1998). Local adaptation in host-parasite systems. Heredity 81: 361-370.

Katiyar SK, Tan Y, Huang B, Chandel G, Xu Y, Zhang Y et al (2001). Molecular mapping of gene $G m-6(t)$ which confers resistance against four biotypes of Asian rice gall midge in China. Theor Appl Genet 103: 953-961.

Kessler A, Baldwin IT (2002). Plant responses to insect herbivory: the emerging molecular analysis. Annu Rev Plant Biol 53: 299-328.

Kirby GC, Burdon JJ (1997). Effects of mutation and random drift on Leonard's gene-for-gene coevolution model. Phytopathology 87: 488-493.

Kliebenstein DJ, Figuth A, Mitchell-Olds T (2002a). Genetic architecture of plastic methyl jasmonate responses in Arabidopsis thaliana. Genetics 161: 1685-1696.

Kliebenstein DJ, Pedersen D, Barker B, Mitchell-Olds T (2002b). Comparative analysis of quantitative trait loci controlling glucosinolates, myrosinase and insect resistance in Arabidopsis thaliana. Genetics 161: 325-332.

Kroymann J, Textor S, Tokuhisa J, Falk K, Bertram S, Gershenzon J et al (2001). A gene controlling variation in Arabidopsis glucosinolate composition is part of the methionine chain elongation pathway. Plant Physiol 127: 1077-1088.

Leonard K (1997). Modelling gene frequency dynamics. In: Crute IR, Holub EB, Burdon JJ (eds) The Gene-for-gene 
Relationship in Plant-parasite Interactions, CAB International: Wallingford. pp 211-230.

Li ZK, Sanchez A, Angeles E, Sukhwider S, Domingo J, Huang $\mathrm{N}$ et al (2001). Are the dominant and recessive plant disease resistance genes similar?: a case study of rice $R$ genes and Xanthomonas oryzae pv. oryzae races. Genetics 159: 757-765.

Luck JE, Lawrence GJ, Dodds PN, Shepherd KW, Ellis JG (2000). Regions outside of the leucine-rich repeats of flax rust resistance proteins play a role in specificity determination. Plant Cell 12: 1367-1377.

Mackey D, Holt III BF, Wiig A, Dangl JL (2002). RIN4 interacts with Pseudomonas syringae type III effector molecules and is required for RPM1-mediated resistance in Arabidopsis. Cell 108: 743-754.

Mauricio R, Rausher MD (1997). Experimental manipulation of putative selective agents provides evidence for the role of natural enemies in the evolution of plant defense. Evolution 51: 1435-1444.

Mauricio R, Stahl E, Korves T, Tian DC, Kreitman M, Bergelson J (2003). Natural selection for polymorphism in the disease resistance gene Rps2 in Arabidopsis thaliana. Genetics 163: 735-746.

McDowell JM, Dhandaydham M, Long TA, Aarts MG, Goff S, Holub EB et al (1998). Intragenic recombination and diversifying selection contribute to the evolution of downy mildew resistance at the RPP8 locus of Arabidopsis. Plant Cell 10: $1861-1874$.

Meyers BC, Shen KA, Rohani P, Gaut BS, Michelmore RW (1998). Receptor-like genes in the major resistance locus of lettuce are subject to divergent selection. Plant Cell 10: 1833-1846.

Meyers BC, Kozik A, Griego A, Kuang H, Michelmore RW (2003). Genome-wide analysis of NBS-LRR-encoding genes in Arabidopsis. Plant Cell 15: 809-834.

Michelmore RW, Meyers BC (1998). Clusters of resistance genes in plants evolve by divergent selection and a birth-and-death process. Genome Res 8: 1113-1130.

Mitchell-Olds T (2001). Arabidopsis thaliana and its wild relatives: a model system for ecology and evolution. Trends Ecol Evol 16: 693-700.

Mopper S, Stiling P, Landau K, Simberloff D, Van Zandt P (2000). Spatiotemporal variation in leafminer population structure and adaptation to individual oak trees. Ecology 81: 1577-1587.

Nakamura R, Mitchell-Olds T, Manasse RS, Lello D (1995). Seed predation, pathogen infection, and life-history traits in Brassica rapa. Oecologia 102: 324-328.

Neema C, Lavigne C, de Meaux J, Cattan-Toupance I, de Oliveira JF, Deville A et al (2001). Spatial pattern for resistance to a pathogen. Theoretical approach and empirical approach at the phenotypic and molecular levels. Genet Sel Evol 33: S3-S23.

Noel L, Moores TL, van Der Biezen EA, Parniske M, Daniels MJ, Parker JE et al (1999). Pronounced intraspecific haplotype divergence at the RPP5 complex disease resistance locus of Arabidopsis. Plant Cell 11: 2099-2112.

Nordborg M, Innan H (2002). Molecular population genetics. Curr Opin Plant Biol 5: 69-73.

Nuismer SL, Thompson JN, Gomulkiewicz R (1999). Gene flow and geographically structured coevolution. Proc $R$ Soc $B$ 266: 605-609.

Parker MA (1991). Nonadaptive evolution of disease resistance in an annual legume. Evolution 45: 1209-1271.

Parniske M, Hammond-Kosack KE, Golstein C, Thomas CM, Jones DA, Harrison K et al (1997). Novel disease resistance specificities result from sequence exchange between tandemly repeated genes at the Cf-4/9 locus of tomato. Cell 91: 821-832.

Raybould AF, Moyes CL (2001). The ecological genetics of aliphatic glucosinolates. Heredity 87: 383-391.
Richly E, Kurth J, Leister D (2002). Mode of amplification and reorganization of resistance genes during recent Arabidopsis thaliana evolution. Mol Biol Evol 19: 76-84

Rossi M, Goggin F, Milligan S, Kaloshian I, Ullman D, Williamson V (1998). The nematode resistance gene $M i$ of tomato confers resistance against the potato aphid. Proc Natl Acad Sci USA 95: 9750-9754.

Roy BA (1993). Patterns of rust infection as a function of host genetic diversity and host density in natural populations of the apomictic crucifer, Arabis holboellii. Evolution 47: 111-124.

Shonle I, Bergelson J (2000). Evolutionary ecology of the tropane alkaloids of Datura stramonium L. (Solanaceae). Evolution 54 778-788.

Sicard D, Buchet S, Michalakis Y, Neema C (1997). Genetic variability of Colletotrichum lindemuthianum in wild populations of common bean. Plant Pathol 46: 355-365.

Sicard D, Woo SS, Arroyo-Garcia R, Ochoa O, Nguyen D, Korol A et al (1999). Molecular diversity at the major cluster of disease resistance genes in cultivated and wild Lactuca spp. Theor Appl Genet 99: 405-418.

Stahl EA, Dwyer G, Mauricio R, Kreitman M, Bergelson J (1999). Dynamics of disease resistance polymorphism at the Rpm 1 locus of Arabidopsis. Nature 400: 667-671.

Stinchcombe JR, Rausher MD (2001). Diffuse selection on resistance to deer herbivory in the ivyleaf morning glory, Ipomoea hederacea. Am Nat 158: 376-388.

Stotz HU, Bishop JG, Bergmann CW, Koch M, Albersheim P, Darvill AG et al (2000). Identification of target amino acids that affect interactions of fungal polygalacturonases and their plant inhibitors. Physiol Mol Plant Pathol 56: 117-130.

Stranger B (2002). Molecular Population Genetics of Arabidopsis Species. PhD Thesis, University of Montana.

Strauss SY, Rudgers JA, Lau JA, Irwin RE (2002). Direct and ecological costs of resistance to herbivory. Trends Ecol Evol 17: 278-285.

Stuthman DD (2002). Contribution of durable resistance to sustainable agriculture. Euphytica 124: 253-258.

Sun Q, Collins CN, Ayliffe M, Smith SM, Drake J, Pryor T et al (2001). Recombination between paralogues at the rp1 Rust resistance locus in Maize. Genetics 158: 423-438.

Thompson JN (1997). Evaluating the dynamics of coevolution among geographically structured populations. Ecology 78: 1619-1623.

Thompson JN (1998). Rapid evolution as an ecological process. Trends Ecol Evol 13: 329-332.

Thompson JN (1999). Specific hypotheses on the geographic mosaic of coevolution. Am Nat 153: S1-S14.

Thompson JN, Cunningham BM (2002). Geographic structure and dynamics of coevolutionary selection. Nature 417: 735-738.

Thrall PH, Burdon JJ (2002). Evolution of gene-for-gene systems in metapopulations: the effect of spatial scale of host and pathogen dispersal. Plant Pathol 51: 169-184.

Tian DC, Araki H, Stahl E, Bergelson J, Kreitman M (2002). Signature of balancing selection in Arabidopsis. Proc Nat Acad Sci USA 99: 11525-11530.

Tian DC, Traw MB, Chen JQ, Kreitman M, Bergelson J (2003). Pleiotropic cost of R-gene mediated resistance in Arabidopsis thaliana. Nature 423: 74-77.

Tiffin P, Gaut BS (2001). Molecular evolution of the woundinduced serine protease inhibitor wipl in Zea and related genera. Mol Biol Evol 18: 2092-2101.

Van der Hoorn RAL, Kruijt M, Roth R, Brandwagt BF, Joosten MHAJ, De Wit PJGM (2001). Intragenic recombination generated two distinct $C f$ genes that mediate AVR9 recognition in the natural population of Lycopersicon pimpinellifolium. Proc Natl Acad Sci USA 98: 10493-10498.

Van der Hoorn RAL, De Wit PJGM, Joosten MHAJ (2002) Balancing selection favors guarding resistance proteins. Trends Plant Sci 7: 67-71. 
Wakeley J, Aliacar N (2001). Gene genealogies in a metapopulation. Genetics 159: 893-905.

Wang KL-C, Li H, Ecker JR (2002). Ethylene biosynthesis and signaling networks. Plant Cell 14(Suppl): S131-S151.

Wei F, Gobelman-Werner K, Moroll SM, Kurth J, Mao L, Wing R et al (1999). The Mla (powdery mildew) resistance cluster is associated with three NBS-LRR gene families and suppressed recombination within 240-kb DNA interval on chromosome 5S (1HS) of barley. Genetics 1533: 1929-1943.

Wilson IW, Schiff CL, Hughes DE, Somerville SC (2001). Quantitative trait loci analysis of powdery mildew resistance in the Arabidopsis thaliana accession Kashmir-1. Genetics 158: 1301-1309.

Zaharieva M, Monneveux P, Henry M, Rivoal R, Valkoun J, Nachit MM (2001). Evaluation of a collection of wild wheat relative Aegilops geniculata Roth and identification of potential sources for useful traits. Euphytica 119: 33-38.

Zhang L, Peek AS, Dunams D, Gaut BS (2002). Population genetics of duplicated disease-defense genes, $h m 1$ and $h m 2$, in maize (Zea mays ssp. mays L.) and its wild ancestor (Zea mays ssp. parviglumis). Genetics 162: 851-860. 